\title{
Habemus Cervesia: Bebendo da Fonte do Empreendedorismo
}

\author{
Elvis Silveira-Martins \\ Universidade Federal de Pelotas - UFPel - RS - Brasil \\ elvis.professor@gmail.com \\ http://orcid.org/oooo-0002-3189-3767 \\ Marina Oliveira Daneluz \\ Universidade Federal de Pelotas - UFPel - RS - Brasil \\ maridaneluz22@gmail.com \\ Cátia Regina Müller \\ Universidade Federal do Rio Grande - FURG - RS - Brasil \\ catia.sls@gmail.com \\ Felipe Köpp Leite \\ Universidade Federal de Pelotas - UFPel - RS - Brasil \\ felipe-kopp@hotmail.com
}

\begin{abstract}
Resumo
O caso apresenta a história de dois jovens que após uma viagem a Europa, resolvem desistir dos cursos superiores e empreender em um negócio novo para o seu município com base nas cervejas experimentadas durante a viagem. Após a superação de diversos obstáculos, típicos do empreendedorismo, apresenta-se a consolidação do empreendimento que atualmente é caracterizado como um dos mais promissores negócios do segmento. Desta maneira, espera-se que os interessados na temática possam ter uma experiência real para ensinamentos, debates e reflexões direcionados a orientação empreendedora. Na sequência, notas de ensino para docentes serão apresentadas, além de sugestões de discussões e questões norteadoras, para contribuir com a aplicabilidade no ambiente educacional. Por fim, apresenta-se fundamentação teórica, que poderá subsidiar as discussões sobre a temática atrelada ao caso para ensino.
\end{abstract}

Palavras-chave: orientação empreendedora, cervejaria, empreendedorismo, artesanal 


\title{
Habemus Cervesia: Driking the source of entrepreneurship
}

\author{
Elvis Silveira-Martins \\ Universidade Federal de Pelotas - UFPel - RS - Brasil \\ elvis.professor@gmail.com \\ http://orcid.org/0000-0002-3189-3767 \\ Marina Oliveira Daneluz \\ Universidade Federal de Pelotas - UFPel - RS - Brasil \\ maridaneluz22@gmail.com \\ Cátia Regina Müller \\ Universidade Federal do Rio Grande - FURG - RS - Brasil \\ catia.sls@gmail.com \\ Felipe Köpp Leite \\ Universidade Federal de Pelotas - UFPel - RS - Brasil \\ felipe-kopp@hotmail.com
}

\begin{abstract}
The case presents the story of two young people who, after a trip to Europe, decided to give up the upper courses and undertake a new business for their county based on the beers they tried during the trip. After overcoming several obstacles, typical of entrepreneurship, there is the consolidation of the enterprise that is currently characterized as one of the most promising businesses in the segment. Still, the venture begins to structure a tourist route aggregating the other players of the market. In this way, it is expected that those interested in the subject can have real experience for teachings, debates and reflections aimed at entrepreneurship orientation. In addition, teaching notes for teachers will be presented, along with suggestions for discussions and guiding questions, to contribute to the applicability in the educational environment. Finally, a theoretical basis is presented, which may support discussions on the theme linked to the case for teaching.
\end{abstract}

Keywords: entrepreneurial orientation, brewery, entrepreneurship, craft 
O posicionamento do empreendedor tem sido foco de muitos estudos e pesquisas com vistas a compreender e justificar através de seu comportamento, as diferenças no êxito dos negócios, dentro do contexto da administração. Uma das abordagens que mais movimenta estudos na área e tem ganhado importância é a Orientação Empreendedora (OE), sugerida inicialmente no estudo de Miller (1983). A OE emergiu da literatura de gerenciamento estratégico e em decorrência desse surgimento, há uma tendência em observar os conceitos provenientes dessa abordagem e utilizá-los para observação do empreendedorismo em nível de organização (Miller, 1983; Covin; Slevin, 1989). A OE compreende o processo de empreender e tudo que ele representa e gera, possuindo características de inovatividade, proatividade e assunção ao risco, de acordo com Miller (1983). Assim, de acordo com Lazarotti et al. (2015), podemos inferir que as dimensões citadas tratam da ação de empreender a partir do método em que a organização atua na tomada de decisões e na gestão da empresa.

Frente a esse panorama relacionando uma das óticas do empreendedorismo com o posicionamento do gestor e o desempenho das empresas, alguns questionamentos norteiam este caso para ensino: por quais razões o empreendimento em questão tornou-se viável e oportuno? Quais características que os dois protagonistas do caso apresentam que contribuíram para o surgimento e ascensão do negócio? De que formas o posicionamento dos gestores afetou a trajetória do negócio em questão? Existiam outras formas de atingir desempenhos satisfatórios que não foram as praticadas pelos atores do presente caso?

Com base nesses questionamentos, surge o caso para ensino, que narra a história de dois amigos de infância que adentram no ramo das cervejarias artesanais, aventurando-se em seu primeiro empreendimento.

\section{O Caso Para Ensino}

Melhores amigos desde a infância, Carlos e Renato moravam próximos na mesma região de Porto Alegre, e tinham ideias muito distintas quanto ao início de suas futuras carreiras aos 22 e 21 anos, respectivamente. As voltas que a vida pode levar surpreenderam os amigos que nunca haviam imaginado tornarem-se empreendedores do ramo cervejeiro.

\section{A Faculdade: Orgulho E Decepção}


O ano de 2006 iniciava e Carlos começava o sonhado curso de arquitetura, enquanto Renato cursava administração. Com uma amizade bastante sólida, os dois costumavam frequentar bares do centro de Porto Alegre para tirar um pouco da pressão dos corridos dias de faculdade conversando e bebendo algo, normalmente as famosas cervejas de massa, uma paixão em comum dos dois rapazes.

Ao final de 2007 chegava o período das últimas avaliações do segundo ano de faculdade, ambos estavam bastante estressados com as provas e trabalhos naquele final do semestre. Foi quando surgiu a ideia que já era costumeira de ir para algum bar.

\section{Os Bares de Porto Alegre: Onde Tudo Começou}

Chegando ao bar, Carlos e Renato pediram um copo de chopp cada um e começaram a conversar como de costume. Mesmo no bar, Renato percebia que uma reprovação estava afetando muito Carlos, então para espantar aquele clima ruim, Renato puxou um novo assunto que já fazia algum tempo que não falavam: “- Cara, o que tu acha de fazermos uma viagem para o exterior, já estou pensando nisto tem algum tempo?”, e o amigo se empolgou: “- Mas como?”, indagou Carlos. Renato então disse: - Já pensei em quase tudo. Temos algum dinheiro guardado, só precisamos ver alguns detalhes e podemos ir... Pensei em irmos para a Europa, principalmente pelo fato de existirem muitos países por perto e assim, conheceríamos muitos lugares”, Renato complementou: “-Eu também preciso, será bom demais para nós. E quanto ao destino, perfeito!”.

\section{A Viagem Que Mudou o Destino.}

Com a aproximação do mês de Julho, era chegada a hora da viagem. Os amigos então embarcaram para seu primeiro destino que era a Bélgica. Depois de algumas horas de voo, chegaram à capital Bruxelas. Na manhã seguinte o guia se apresentou e os três seguiram pelos principais pontos turísticos da capital Belga. Ao cair à noite, e o guia havia deixado Carlos e Renato no hotel, e ambos decidiram ir a um pub. Pediram uma cerveja cada e começaram a conversar. “- Um brinde a nossa viagem!”, exclamou Renato, e Carlos disse: “- Cheers, meu amigo!”. Muita conversa rolava, e após algumas cervejas, ambos foram para seus quartos no hotel. Renato pensava algumas coisas sobre a noite, mas logo caíra no sono. 
Já Carlos antes de dormir, pensava consigo mesmo: “- Nossa, eu nunca tinha provado uma cerveja tão boa assim... Foi simplesmente incrível”.

Após três dias de passeio na Bélgica, foram para o aeroporto à noite para seguir para Alemanha. Durante a manhã, os jovens descansaram e saíram do hotel para um passeio por Berlim com seu guia, que durante o passeio repassou uma ideia: “- Amanhã podemos pegar um ônibus, ir até a região de Colônia, aproveitar o dia e a noite virmos de volta para Berlim, e na noite seguinte ir para Londres”. “- Por que a cidade de Colônia?”, perguntou Renato, que embora quisesse conhecer o país, não entendeu a escolha do guia. Logo ouviu a resposta: “- Eu percebi na primeira noite em Bruxelas que vocês foram para um pub beber algo, então Colônia é uma região conhecida por excelentes cervejas artesanais, por isso pensei no lugar, e também passamos por várias cidades no trajeto”. Renato e Carlos se entreolharam e concordaram com o guia. Àquela altura, Carlos e Renato começavam a compreender o sabor excepcional da cerveja que tomaram.

Logo que desceram do ônibus perguntaram ao guia onde encontrar as bebidas. $\mathrm{O}$ guia respondeu a eles: “- Em praticamente todo local que vocês irem aqui, terá a cerveja artesanal...", e continuou “- Vou deixar vocês livres para experimentar, às $17 \mathrm{~h}$ me encontrem aqui para andarmos pela cidade e depois voltarmos para Berlim. Lembrem, Colônia é uma cidade extremamente histórica, os mais antigos já bebiam cerveja por aqui há mais de mil anos”. No primeiro local que avistaram aberto, solicitaram cerveja artesanal: “- Duas, por favor”. Depois de beber cerca de metade de uma das garrafas, Carlos puxou assunto: “- Renato, não existe nada semelhante com isso em Porto Alegre”, “- Com certeza, já frequentamos vários bares e em nenhum tinha algo parecido com isto”, disse Renato e prosseguiu em meio a alguns risos: “- Já pensou que, se fizéssemos algo parecido, conseguiríamos lucrar com isto?!”, Carlos concordou exclamando: “- Verdade, depois dessa cerveja não quero mais saber das que sempre tomamos, e ainda poderemos ganhar dinheiro vendendo esta experiência para outros e com isto pagar a nossas cervejas!”.

Á noite retornaram para Berlim e no dia seguinte partiram para Londres, onde também degustaram outras excelentes cervejas artesanais. Após a estadia de três dias em Londres, pegaram seu voo de volta para o Brasil felizes pela viagem e também por terem trazido um algo mais que nunca tinha passado por seus planos - uma ideia para por em prática além de muitas anotações sobre as cervejas que haviam experimentado.

\section{Uma Ideia Cria Forma: Cervejaria Artesanal}


Ao reencontrarem suas famílias, vieram à tona aqueles assuntos de como foi a viagem e Carlos logo comentou: “- A viagem foi ótima, tudo foi muito bem”, “- O Carlos tem razão e nós dois queremos conversar uma coisa com vocês”, Renato, ansioso, finalizou. Dessa forma, todos rumaram para a casa de Renato.

Já em casa e com o café servido, a conversa que se iniciara no saguão do aeroporto prosseguiu. “- E então, meninos... Sobre o que querem falar?”, começou Mateus “- Pois é, Pai, eu e o Carlos conversamos bastante sobre uma parte da viagem...”, disse Renato, e prosseguiu: “- Fomos a alguns bares, provamos uma cerveja diferente de tudo que vocês já imaginaram. Começamos falando na brincadeira de trazer isso para Porto Alegre, e estamos com a ideia de sair da imaginação e se tornar realidade! Pensamos em começar um negócio”. Carlos vendo a iniciativa de Renato continuou: “- Gostamos muito das nossas faculdades, sabemos que vocês sempre quiseram que estivéssemos lá, mas tenho o mesmo sentimento do Renato, sobre ter um negócio nosso”.

Um longo período de silêncio seguiu durante o café. Ainda um pouco em choque, Alberto, o pai de Carlos disse: “- Então estão querendo largar a faculdade para uma ideia que talvez não dê certo?”, “- Quero dizer, trocar o certo pelo duvidoso?”, perguntou em um tom de pouco amigos. Carlos tomou a dianteira nesse momento e exclamou: “- Sim, Pai!”, “- É isso que estamos pensando em fazer, temos chances de dar certo, como também de não dar... Aquela cerveja é uma coisa que não existe aqui, e com o tempo, tanto eu como o Renato, temos certeza que nossa ideia venderá”, finalizou falando da mesma forma que seu pai e mostrou algumas fotos de lugares e anotações realizadas. Vendo o teor e tons de voz da conversa, as mães de Carlos e Renato os incentivaram a correr atrás do que queriam.

\section{Novos Estudos, Novas Perspectivas: Aprendendo A Empreender}

Em 2008, Renato e Carlos foram até a faculdade e trancaram suas matrículas. Era agosto quando Carlos começou seu curso de cervejeiro. Enquanto Carlos estudava, Renato conseguiu um emprego como garçom em um restaurante próximo a sua casa, para juntar uma quantia de dinheiro para colocar o negócio em prática.

No fim de 2010, Carlos concluiu seu curso cervejeiro e Renato já havia juntado um bom dinheiro para dar início na cervejaria, só que tinham algumas questões pendentes, como local, equipamentos, nome da empresa. Durante uma conversa na noite de conclusão 
do curso, Renato comentou: “-Carlos, após a virada do ano, podemos começar a adquirir alguns equipamentos”, Carlos continuou o raciocínio do amigo com algumas questões: “Mas onde guardar? Qual vai ser o nome da nossa cervejaria?”, “- Carlos, a sua garagem não está totalmente desocupada?”, Carlos um pouco cauteloso disse: “- Está sim, mas não entendi onde tu quer chegar, Renato”,“- Simples!”, exclamou Renato e prosseguiu: “- Foi lá que nos reunimos muitas vezes para articular a viagem, por quê não começar lá a cervejaria?”. Carlos empolgado respondeu: “- Verdade, Renato! Não tinha pensando nisso. Vamos começar lá então", concluiu Carlos.

O ano de 2011 começava já agitado para Carlos e Renato. Carlos chegou a sua garagem e começou a fazer a primeira cerveja artesanal. Após concluir o início do processo, Carlos sorridente disse a Renato: “- Bom, essa minha parte está feita, agora temos que esperar 12 dias até a cerveja estar pronta”, Renato feliz com a primeira "produção" continuou: “- Agora, eu vou começar o meu curso sobre como gerir uma cervejaria. Curso era durante a noite, e durante o dia vou sair a oferecer aqui pela vizinhança”. “- Boa Renato!", disse Carlos.

Já Renato saiu para procurar cursos sobre gestão de cervejarias. Então se matriculou e na semana seguinte seu curso já iria iniciar. Percebeu logo nas primeiras aulas que o empreendimento não seria nada muito fácil como pensavam, já que, por exemplo, o imposto sobre cervejas é de cerca de 60 a 70\% do resultado bruto. Essas e outras questões começaram a instigar Renato a pensar em novas ideias e caminhos pelos quais poderiam seguir com seus negócios e aproveitar oportunidades para diminuir os riscos da atividade.

\section{Entrando no Mercado: o Percalço Inicial}

Carlos se concentrava muito tentando criar receitas diferenciadas. Em todas as manhãs e tardes, os amigos estavam juntos na garagem, e Renato saia para oferecer a cerveja para vizinhos e amigos. A produção era praticamente mínima, cerca de 500 litros por mês, mas o negócio começava a dar resultados, e em janeiro de 2012, quando o curso de Renato terminou, eles perceberam que na região da sua vizinhança a cerveja já começava a ser mais aceita, o que fez com que eles parassem para discutir “- Já estamos há 1 ano na garagem, será que já não está na hora de abrirmos a produção em um lugar maior? Escolher um nome para nossa cervejaria?”, Carlos perguntava para Renato, e ele imediatamente 
respondia: “- É... acho que está na hora de regularizarmos a situação, podemos achar algum lugar aqui na zona sul...”.

\section{Novos Rumos, Novos Horizontes: te Batizo BierKunst}

Depois de quase desistir de procurar um prédio com uma boa localização, Renato disse: “- Carlos vamos deixar isso para...”, “- Espera, Renato!”, falou Carlos aumentando o tom de voz: “- Olhe para o lado... Portões grandes, e disponível. “- Parece um bom lugar, e o único disponível aqui na redondeza, vou anotar o número e pela manhã ligamos" falou Renato..

Na manhã seguinte, Renato ligou e solicitou informações como tamanho e preço do aluguel. Chegando à imobiliária, a corretora que havia falado com Renato já os aguardava: “- E então, rapazes! O que acharam?”, Carlos e Renato conversavam entre si, depois de um pequeno tempo de silêncio, Renato respondeu: “- Gostei bastante, tem uma boa localização, o preço é bom e o espaço já é maior de onde estamos atualmente”.

Chegando à garagem, e Carlos indagou: “- Renato, se já estamos interessados no lugar, precisamos escolher um nome para a empresa: "-O nome podemos começar a escolher agora, o aluguel já ligamos até o fim da semana, e precisaremos adquirir máquinas novas”. Carlos continuou o raciocínio: “- E com o aumento da produção, irei criar novas receitas e precisaremos contratar pelo menos um funcionário para me auxiliar”. Renato concordou com os pontos destacados por Carlos e disse: “-E quanto ao nome da empresa, como podemos fazer?”, “- Pensei em algo que envolvesse talvez: 'a arte da cerveja”, prosseguiu Renato. Carlos havia gostado da ideia, porém tinha algo melhor: “-E por que não colocar esse nome em uma das línguas dos países que visitamos? Afinal foi em nossa viagem que a ideia da cervejaria surgiu. Renato concordando começou a testar no tradutor da internet como o nome ficaria. Renato chamou Carlos: “- Olha só, tem essas duas possibilidades, pois uma das línguas oficiais da Bélgica é o Alemão: 'BeerArt', em inglês e 'BierKunst', em alemão. Qual tu prefere?”, Carlos não demorou muito e respondeu: “-Acho que BierKunst ficou mais chamativo e adequado que o primeiro nome”. Como Renato havia deixado para Carlos ter a resposta definitiva, ele apenas concordou e falou em tom alto: “Então te batizo de BierKunst erguendo uma garrafa que estava sob a mesa”.

\section{O Começo Oficial e Um Novo Obstáculo}


Em março de 2012, o novo prédio da cervejaria já estava alugado e os sócios necessitavam novos equipamentos. Um primeiro funcionário foi contratado auxiliar no processo de produção que agora poderia passar de 500 litros mensais para até três mil litros. Carlos também criou dois novos tipos de cerveja. Entre suas criações estavam uma cerveja que era produzida com maltes selecionados, trigo, que diferenciava-se desta pelo amargor mediano que apresentava ao paladar.

Ao final de 2012, Renato estava ocupado com a finalização das contas do ano da cervejaria, e conforme havia estudado, a empresa sobrevivia com apenas $40 \%$ das receitas brutas. Mesmo com essa alta carga tributária, a cervejaria mantinha todas suas responsabilidades em dia, pois suas vendas cresciam exponencialmente, contando com os bares que eram fiéis a empresa e tornaram-se clientes assíduos da BierKunst, muito em função da diferenciação das cervejas, aproximando-se muito das cervejas degustadas na viagem a Europa.

Com o tempo e aumento exponencial nas vendas, Carlos não demorou a conversar com Renato sobre uma mudança no endereço da empresa, além de mais tanques fermentadores. Renato um pouco pensativo com as contas da cervejaria respondeu ao seu sócio: “- É verdade, Carlos.”, e prosseguiu “- Mas também precisamos encontrar maneiras de divulgar ainda mais a nossa cerveja, lembre-se, com o espaço maior, teremos um custo fixo maior!”, exclamou Renato. “- Quanto a essa maior divulgação, eu tenho uma ideia...”, disse serenamente Carlos. “- Em março do ano que vem, vai ter o primeiro concurso brasileiro de cervejas artesanais, podemos usar essa oportunidade para termos uma divulgação nacional da nossa cerveja”. Renato imediatamente concordou.

\section{Divulgação Nacional: O Concurso Brasileiro de Cervejas Artesanais}

A data do concurso chegava, Carlos, Renato e o funcionário da cervejaria viajaram para Blumenau-SC para organizar a preparação das cervejas para o concurso. Diversos juízes e pessoas de todas as regiões do Brasil passavam pela banca da BierKunst para julgar e experimentar a cerveja. Ao chamar as pessoas: “- Oi, você conhece a BierKunst?”, a maioria dos visitantes respondiam que não, então Carlos explicava sobre a empresa e sua cerveja: “- Essa é uma cerveja que criamos há pouco tempo. Em uma viagem que fizemos a passeio para a Europa, conhecemos cervejas que nunca havíamos provado em Porto Alegre, 
e resolvemos criar algo semelhante...”. Após provarem as pessoas se maravilhavam com o sabor da cerveja BierKunst e solicitavam entregas para fora do Rio Grande do Sul e eles passavam seus contatos.

Neste primeiro concurso a BierKunst acabou sem faturar nenhuma medalha, porém conseguiu uma divulgação nacional de sua marca. Já organizando as coisas para voltar, Carlos puxou assunto: “- Viu só, Renato! Eu disse que era uma grande forma de divulgação vir para cá”, Renato prosseguiu: “- Verdade, Carlos! Com essa divulgação toda e todos os telefones que passei para os visitantes do evento, precisaremos mesmo de um novo lugar para nossa cervejaria”.

\section{Consolidação no Mercado: a Cervejaria Mostrava Resultados}

A grande divulgação que ocorrera no concurso rendeu excelentes frutos, tanto que Renato não conseguia dar conta dos pedidos, então desabafou: “- Carlos, assim não está rendendo mais, precisamos urgentemente de mais pessoas”, “-Isso mesmo, Renato! Está tudo corrido demais, concordou Carlos.

Em junho de 2013, Carlos e Renato então decidiram alugar um novo local e comprar novos equipamentos. Contrataram uma secretária para auxiliá-lo nos pedidos e três funcionários muito qualificados para a produção, e assim Carlos poderia se dedicar a criar novas cervejas e inspecionar a produção. A produção conseguiu dar um salto para até 7 mil litros mensais de produção cervejeira.

Com as novas participações no concurso de cerveja artesanal de Blumenau-SC e em feiras pelo estado do Rio Grande do Sul, as vendas seguiam crescendo exponencialmente, devido a criação de uma nova variedade de cerveja criada por Carlos, que se destacava pelo aroma, por exemplo, de melão e também pela utilização de aveia nas receitas, o que provoca mais robustez e retenção de espuma à cerveja. As receitas de cerveja receberam premiações com a medalha de ouro em 2015 e prata em 2016 no Concurso Brasileiro de Cervejas Artesanais. Quando degustaram pela primeira vez a criação de Carlos, os amigos transportaram-se automaticamente para a legendária e histórica Colônia, na Alemanha: "Carlos, sabe o que essa cerveja me lembrou? Sinto como se fôssemos aqueles antigos moradores de Colônia, que degustavam cerveja desde os tempos mais antigos, e apreciavam o sabor desse produto, como o guia nos contou”, exclamou Renato. Carlos, sentindo a sinceridade e sensibilidade do amigo exclamou: "Habemus cervesia, meu amigo!", 
"Habemus cervesia, com toda a certeza", concordou o outro, tornando esse cumprimento, uma espécie de saudação única entre eles.

Cada vez mais empolgados, Renato já estava estudando há dias um prédio localizado junto a sua cervejaria, separado apenas por uma porta. Esse prédio estava sendo desocupado, anteriormente funcionava uma metalúrgica no local que estava no mercado há mais de vinte anos, mas que estava fechando as portas no momento. Ali, ele viu uma nova chance de negócio, então chamou Carlos: "Renato levantou-se da cadeira de sua sala e repassou sua ideia: “-Pense bem, já estamos mais equilibrados no nosso negócio, vejo ali uma oportunidade de abrirmos uma lojinha para nossa cervejaria, um espaço para eventos, me entende?”, Carlos começou a entender onde Renato queria chegar: “- E nesses eventos trazer Dj’s e foodtruck’s?”, “- Isso mesmo”, respondeu Renato.

\section{Novas Conquistas: Habemus BierKunst e Cervesia!}

Em fevereiro de 2016, o pavilhão já estava alugado e começava a ser organizado para os eventos. Renato deu uma ideia ao falar quando seria o primeiro evento: "-Agora em março a cervejaria vai comemorar seu quinto aniversário desde que abrimos de forma oficial”. Carlos exclamou:“- Excelente ideia, Renato!” e seguiu: "Podemos realizar a divulgação por meio das redes sociais, e disponibilizar mapas”. Contrataremos um Dj e também alguns foodtruck's para se alocarem aqui dentro”, disse Renato. “- Será inesquecível! Habemus cervesia meu amigo!”, exclamou Carlos, sendo saudado por Renato “Habemus cervesia, certamente!”.

Atualmente, a BierKunst segue como uma microcervejaria porto-alegrense, gerando quatro empregos diretos e com um processo automatizado, pretendendo dentro dos próximos três anos aumentar o número de tanques fermentadores para possibilitar a produção de até 10 mil litros mensais, e consequentemente aprimorar sua estratégia de vendas, além de gerar novos empregos na área de produção. O novo pavilhão, inaugurado em março de 2016 funciona todos os sábados e domingos à noite, com atrações de foodtruck's, chopp's e outras cervejas da BierKunst, promovendo assim uma aproximação do cliente com a empresa. A concorrência não é um desafio considerado pela cervejaria, pois embora existam diversas cervejarias artesanais espalhadas pela cidade, cada cerveja é feita de uma maneira diferenciada, e o que é destacado entre suas estratégias de negócio são a diferenciação e a qualidade. Ademais, os sócios projetam uma rota turística 
interligando os concorrentes e, com isto, oportunizando a manutenção de todos os empreendimentos cervejeiros da cidade. O principal diferencial da cervejaria BierKunst são seus sócios inovadores e proativos dispostos a investirem incansavelmente na cervejaria, cada um com suas qualidades e características, mantendo o que mais movia àquela ideia: tornarem-se uma cervejaria diferenciada.

\section{Notas pedagógicas - orientação para professores}

\section{Objetivos Educacionais}

O presente caso para ensino tem como objetivos de aprendizado: expor a realidade do segmento das cervejarias artesanais, desde sua criação, trajetória, dificuldades e barreiras iniciais, processos internos e organização e desempenho ao longo dos anos; caracterizar o comportamento dos empreendedores do negócio e tomadores de decisão; demonstrar as principais incertezas ambientais do ambiente de negócio; aproximar a realidade do ambiente de negócio, a nível empírico, com o ambiente educacional e de aprendizado (teórico).

\section{Utilizações Recomendadas}

Esse caso para ensino foi elaborado para fins de aplicação em disciplinas que abordem a temática do empreendedorismo, contexto organizacional, planejamento estratégico, tomada de decisões, estratégia, tanto em nível de graduação quanto pósgraduação. Recomenda-se que esse caso seja utilizado em classes que já tenham conhecimento prévio básico e introdutório acerca do tema.

\section{Fonte e Métodos de Coleta}

A fonte para a coleta de dados é a própria cervejaria que, em função de solicitação dos proprietários, teve seu nome verdadeiro ocultado. Já para a coleta das informações foram realizadas entrevistas que foram gravadas, transcritas e descritas no formato da metodologia de caso para ensino. 


\section{Sugestões de Questões Para Discussão}

- O cenário econômico atual é favorável para a implantação de um empreendimento nos moldes do relatado? Se sim, justifique. Se não, qual o segmento que melhor possui viabilidade nos dias de hoje?

- Quais principais características que cada um dos gestores do empreendimento apresentaram, durante a trajetória da empresa desde o período inicial, até os dias atuais?

- Quais características de cada um dos gestores mais chamaram sua atenção? Você acha que algum deles é um empreendedor? Justifique sua resposta.

- Você concorda com as tomadas de decisões realizadas por Carlos e Renato? Se não, como você, gestor de uma cervejaria artesanal, procederia por algumas questões apontadas no texto, como por exemplo, na necessidade de possuir um diferencial frente às demais cervejarias?

- Quais as principais dificuldades que a BierKunst enfrentou para ser reconhecida no mercado?

- Descreva as principais características de Carlos e Renato que facilitaram o surgimento de novas ideias e novos produtos?

- Você acredita que a amizade entre os dois sócios pode ser um atenuante de dificuldades no gerenciamento de um negócio? Em sua opinião, isso ocorreu na trajetória da BierKunst?

\section{Dinâmica da Aula.}

O texto deve ser apresentado aos alunos e disponibilizado com antecedência, para que possam fazer uma leitura profunda do caso, interpretando os acontecimentos e atitudes dos gestores, e tenham esclarecimento total da trajetória da empresa. Recomenda-se ainda que seja solicitado um resumo do caso.

Durante a aula, o docente inicialmente pode solicitar que os alunos discutam as diferentes perspectivas e posicionamentos. Posteriormente, as questões podem ser comparadas e discutidas em sala de aula. Após, recomenda-se que os diferentes posicionamentos sejam destacados, preferencialmente na lousa, ou projetor, ou papéis adesivos, para que possam ser contrastados ao final da atividade com a teoria sobre orientação empreendedora. 


\section{Análise do caso}

\section{Orientação Empreendedora}

O conceito de Orientação Empreendedora (OE) surge na identificação de posturas ou comportamentos organizacionais que possam propiciar maior ou menor capacidade de empreender (Santos \& Alves, 2009). A operacionalização da orientação empreendedora tem sido consistente nas dimensões propostas por Miller (1983), com as características de comportamento inovativo, proatividade e propensão a correr riscos.

A inovatividade, considerada item fundamental do processo de empreendedorismo (Covin \& Miles, 1999), representa o desenvolvimento de novos produtos, processos, tecnologias e ações, criados pela organização e gestores com vistas a inovar e iniciar atividades.

A proatividade, para Lumpkin e Dess (1996), é o oposto da passividade e está intimamente relacionada com a inovatividade em decorrência de aquela sugerir ênfase em novas atividades ou novos produtos. A dimensão da proatividade assemelha-se com as ideias sugeridas por Milles e Snow (1978) que caracterizam o tipo prospector de comportamento estratégico, que possui capacidade importante de encontrar e explorar novos produtos e possibilidades no mercado e são impulsionadores de mudanças no ambiente organizacional.

Para além da inovatividade e proatividade, a terceira dimensão proposta nesse contexto é a assunção ao risco, relacionada às práticas de aventurar-se em novos negócios, novas ações, novos processos, atitudes e atividades ainda não tão esclarecidas e estabelecidas a nível empresarial. De acordo com Wiklund e Sheperd (2005), assumir riscos está associado a disposição de dedicar maiores recursos a projetos onde o custo da falha pode ser elevado. Além disso, ela implica a utilização de recursos em projetos onde os resultados são de caráter desconhecido ou não aplicável.

A relação dessas dimensões com o desempenho é discutida amplamente no âmbito da administração. Individualmente, cada dimensão da orientação empreendedora pode ter influência positiva universal sobre o desempenho da organização (Wiklund \& Sheperd, 2005). Empresas proativas, que criam, inovam e introduzem tecnologias e processos, aventurando-se e antecipando barreiras futuras, podem gerar desempenho extremamente 
significativo e até mesmo serem vistas como motores de crescimento econômico, tamanha associação com o desempenho.

De acordo com Silveira-Martins e Vaz (2017, p. 2) a orientação empreendedora pode ser entendida como "a capacidade da gestão conduzir a organização para obter vantagem competitiva, posicionando-se à frente dos seus concorrentes, agregando valor aos produtos/serviços, antecipando as demandas de mercado, mesmo que seja necessário assumir riscos. Em complemento, Silveira-Martins, Mascarenhas e Muller (2017) afirmam que a orientação assumida pelo tomador de decisões impacta diretamente sobre a vitalidade das organizações.

Segundo, Silveira e Silveira-Martins (2016), em levantamento realizado sobre orientação empreendedora, o construto é formado em 68,75\% das pesquisas pelas dimensões: inovatividade; proatividade e assunção de riscos. Já as dimensões inovatividade; proatividade; assunção de riscos, autonomia e agressividade competitiva, foram identificadas em 24,10\% dos experimentos. Por outro prisma, em 1,78\% a orientação empreendedora foi pesquisada considerando a proatividade e assunção de riscos, enquanto $5,35 \%$ utilizaram-se de diferentes abordagens. 


\section{Referências}

Covin, J. G. \& Miles, M. P. (1999). Corporate entrepreneurship and the pursuit of competitive advantage. Entrepreneurship Theory and Practice, 23(3). 47-63.

Covin, J. G., \& Slevin, D. P. (1991). A conceptual model of entrepreneurship as firm behavior. Entrepreneurship: Theory \& Practice, 16(1). 7-25.

Lazarotti, F., Silveira, A. L. T., Carvalho, C. E., Rossetto, C. R. \& Sychoski, J. C. (2015). orientação empreendedora: um estudo das dimensões e sua relação com desempenho em empresas graduadas. Revista de Administração Contemporânea, 19(6). 673-695.

Lumpkin, G. T. \& Dess, G. (1996). Clarifying the entrepreneurial orientation construct and linking it to performance. Academy of Management Review, 21(1), 135-172.

Miles, R. E. \& Snow, C. C. (1978). Organizational strategy, structure, and process. Palo Alto, CA, USA: Stanford University Press.

Miller, D. (1983). The correlates of entrepreneurship in three types of firms. Management Science, 27(7). 770-791.

Santos, A. C. M. Z. (2009). Dimensões da orientação empreendedora e seus diferentes impactos no desempenho de empresas instaladas em incubadoras tecnológicas da região sul do brasil. In Encontro Nacional de Pós Graduação e Pesquisa em Administração, São Paulo, 33.

Schildt, H. A., Zahra, S. A., \& Sillanpää, A. (2006). Scholarly communities in entrepreneurship research: a co-citation analysis. Entrepreneurship: Theory \& Practice, 30(3). 399-415.

Silveira-Martins, E., \& Vaz, C. S. (2017). Orientação empreendedora associada ao desempenho: uma análise de agroindústrias do RS. Revista Agroalimentaria, 23(44). 95-105.

Silveira-Martins, E., Mascarenhas, L. E., \& Muller, C. R. (2017). Orientação empreendedora uni/multidimensional como estratégica precedente da capacidade gerencial. Revista Brasileira de Gestão e Inovação, 4(2). 105-124. 
Silveira, B. R., \& Silveira-Martins, E. (2016). Orientação empreendedora: uma análise bibliométrica em periódicos nacionais e internacionais. Revista FACES, 15(4). 100-126.

Wiklund, J., \& Shepherd, D. (2005). Entrepreneurial orientation and small business performance: a configurational approach. Journal of Business Venturing, 20(1). 71-91. 